\title{
EDITORIAL: IS MITRAL VALVULOPLASTY ALWAYS INDICATED IN PATIENTS WITH POOR LEFT VENTRICULAR FUNCTION AND ISCHEMIC CARDIOMYOPATHY?
}

Lynda L. Mickleborough, MD

In this issue of the Journal, Di Donato and colleagues present 1-year follow-up data in 44 patients who underwent the Dor procedure (see page 91). They found that deterioration of mitral valve function was more frequent in patients with larger preoperative ventricular volumes and decreased eccentricity indexes (increased sphericity) preoperatively.

The issue of what to do for mitral regurgitation (MR) associated with left ventricular ( $\mathrm{LV}$ ) dilatation in patients with a low ejection fraction is a very important one. Dr Di Donato and colleagues have attempted to link MR after the Dor procedure with changes in ventricular shape and volume. The strength of their approach is that they have serial angiograms (preoperative, early, and 1-year postoperative studies) in many of their patients. The disadvantage, however, is that they have assessed MR by analyzing the ventriculograms. This is a rather insensitive method for detecting MR, especially in patients who have a dilated heart. Use of Doppler echocardiography would have given much more accurate information with regard to valve function.

My colleagues and I have been surprised to find significant MR on preoperative echocardiographic evaluation in $45 \%$ of patients accepted for aneurysm repair who had no MR obvious on the ventriculogram. ${ }^{1}$ In many of these patients, ventricular remodeling and

From the Department of Surgery, Toronto General Hospital, Toronto, Ontario, Canada.

Received for publication Sept 20, 2000; accepted for publication Sept 29, 2000.

Address for reprints: Lynda L. Mickleborough, MD, Department of Surgery, Toronto General Hospital, 200 Elizabeth St, Eaton North-EN 13-217, Toronto, Ontario M5G 2C4, Canada.

J Thorac Cardiovasc Surg 2001;121;97

Copyright () 2001 by The American Association for Thoracic Surgery

$0022-5223 / 2001 \$ 35.00+0 \quad \mathbf{1 2 / 1 / 1 1 2 7 4 2}$

doi: $10.1067 / \mathrm{mtc} .2001 .112742$ revascularization alone significantly improved mitral valve function postoperatively. This approach was associated with good symptomatic improvement and excellent 5-year survival in our series.

I believe a word of caution is needed in properly interpreting the results reported by Di Donato and colleagues and in evaluating their conclusions. In their series, at 1 year, half of the patients with MR had only minor MR (grade 1). It is not clear to me that grade $1 \mathrm{MR}$ will necessarily translate into a poor clinical result or decreased survival. I agree with Di Donato's group that after myocardial infarction, preoperative MR and marked LV dilatation probably indicate more extensive adverse ventricular remodeling, which would have a negative impact on longterm results. I also agree that their observations support the argument for earlier surgical intervention in these patients. However, whether the addition of a valvuloplasty procedure is indicated in all patients with preoperative MR undergoing aneurysm repair requires further study. The relationship between MR and changes in ventricular shape and size remain complex and poorly understood. For example, Di Donato and colleagues have demonstrated that the diastolic shape of the ventricle became more spherical after the Dor procedure, yet systolic function appeared to improve. The impact of changes in ventricular size and shape after surgical ventricular remodeling on functional result and long-term survival are still to be established. Further studies are needed before definite recommendations can be made about case selection and optimal surgical technique for LV remodeling with or without mitral valve repair.

\section{REFERENCE}

1. Mickleborough LL, Maruyama H, Liu P, Mohamed S. Results of left ventricular aneurysmectomy using a tailored scar excision and primary closure technique. J Thorac Cardiovasc Surg 1994;107: 690-8. 